\title{
Cuatro preguntas y tres diálogos: La obra escrita de Eugenio Barba
}

Lluís Masgrau*

RESUMO: O artigo de Lluis Masgrau visa demarcar as principais áreas de interesse do diretor teatral Eugenio Barba em sete de seus livros, de modo a abarcar sua visão sobre o teatro. Esses escritos derivam das experiências profissionais de Barba marcadas pelo diálogo com três grandes vertentes da cultura teatral do séc. XX - a Grande Reforma (Stanislavski, Grotowisk, Living Theater etc), o teatro clássico asiático e o teatro de grupo latinoamericano -, balizadas por suas quatro perguntas fundamentais: "onde," "por que", "como" e "para quem" atuar; donde os quatro níveis do ofício: a aprendizagem, a busca de um sentido pessoal, a construção da técnica e o "valor", o qual resulta, grosso modo, do compartilhamento com o espectador do sentido pessoal expresso pelo ator. Concluindo que a identidade profissional de Barba adquirida ao longo de seu caminho é a "conquista da diferença".

PALAVRAS-CHAVE: Eugenio Barba, ofício do ator, teatro laboratório, antropologia teatral.

ABSTRACT: The article by Lluis Masgrau aims to demarcate the main areas of Eugenio Barba's interest in seven of his books, so as to encompass his thetrical view. These writings derive from the professional experiences of Barba marked by the dialogue with three great strands of 20th-century theatrical culture - the Great Reformation (Stanislavski, Grotowisk, Living Theater, etc.), Asian classical theatre

\footnotetext{
*Lluís Masgrau é doutor pela Universidade de Barcelona, foi professor do Instituto do Teatro em 1997-98, chefe do Departamento de Teoria e História (2007-11 e 2013-14) e coordenador do Mestrado de Estudos Teatrais (2010-13). É membro do Conselho de Pesquisa do IT. Entre 1992-96 trabalhou no Odin Teatret como assistente de Eugenio Barba; desde 1998 é membro da equipe científica da International School of Theatre Anthropology (ISTA). Publicou numerosos artigos em revistas especializadas da Europa e América. Foi professor convidado em diversas universidades e escolas superiores de teatro da Europa e América.
} 
and Latin American group theatre - marked by his four fundamental questions: "where", "why", "how", and "for whom" to act; Thus the four levels of the craft: learning, the search for a personal sense, the construction of a technique and "value", which results, roughly, from sharing the personal meaning expressed by the actor with the audience. Concluding that Barba's professional identity gained along his path is the "conquest of difference."

Keywords: Eugenio Barba, actor's craft, laboratory, theatrical anthropology.

La obra escrita de Barba tiene un carácter heterogéneo y aparentemente disperso. A nivel formal, su punto de partida son los numerosos textos individuales que ha publicado entre 1962 y la actualidad, 2014 (unos 260). Pero a partir de los años noventa, Barba crea una serie de libros a través de los cuales organiza progresivamente su pensamiento. La mayoría de estos libros son antologías de textos publicados anteriormente o libros que funden en su discurso materiales inéditos y materiales ya publicados. De esta forma Barba ha utilizado sus libros más importantes para destilar poco a poco la masa de sus textos individuales y sus ideas fundamentales.

Los siete libros que contienen el núcleo de su pensamiento teatral son: El arte secreto del actor (Artezblai, Bilbao 2012)1 ; Teatro. Soledad, oficio, revuelta (Catálogos, Buenos Aires 1997 y Escenología, México D.F. 1998)2; La canoa de papel (Artezblai, Bilbao 2013); La tierra de cenizas y diamantes (Octaedro, Barcelona 2000); Arar el cielo. Diálogos latinoamericanos (Fondo Editorial Casa de las Américas, La Habana 2002); Quemar la casa (Artezblai, Bilbao 2010); La conquista de la diferencia (Editorial San Marcos, Lima 2008 y Alarcos, La Habana 2012)3. Estos libros marcan un punto de llegada que organiza los temas más importantes de Barba en grandes áreas de reflexión. Analizando cuáles son estas áreas y cómo se relacionan podemos formular la estructura profunda del corpus barbiano y la visión teatral que hay implícita en ella. Éste es el objetivo del artículo.

\section{Cuatro preguntas y tres culturas teatrales}

Barba explica a menudo que cualquier hombre o mujer de teatro debe responder, explícita o implícitamente, a cuatro preguntas claves: "dónde" hacer teatro, "por qué," "cómo" y "para quién." Éste es el principal eje que vertebra su obra escrita. Además de éste, existe un 
segundo eje determinado por el diálogo profesional que Barba ha mantenido con tres grandes culturas teatrales.

La primera es una parte importante de la cultura teatral occidental reciente que él llama la Grande Reforma, retomando el término utilizado por la historiografía polaca. Esta mutación se despliega a lo largo del siglo XX encarnada en una serie de reformadores que reinventaron de una forma muy personal la práctica del teatro. En esa cultura aparecen encuadrados Stanislavski, Meyerhold, Copeau, Decroux, Artaud, Brecht, Grotowski o el Living Theatre, entre otros.

La segunda gran cultura teatral con la que Barba ha interactuado intensamente es el conjunto de los teatros clásicos asiáticos. Él entró en contacto con esta cultura cuando estaba realizando su aprendizaje con Grotowski. En 1963 Barba viajó a la India y los avatares del viaje le Ilevaron a Kerala, donde "descubrió" el kathakali. El diálogo con los teatros clásicos asiáticos recorre de arriba a bajo toda la carrera profesional de Barba, desde su aprendizaje hasta la actualidad.

La tercera cultura teatral que ha influenciado poderosamente la identidad profesional de Barba es la del teatro de grupo latinoamericano. En 1976 el Odin Teatret viajó por primera vez a Latinoamérica invitado al Festival de Caracas. Ahí Barba anudó lazos de amistad y colaboración con una serie de grupos y artistas teatrales latinoamericanos. Desde entonces hasta la actualidad el diálogo de Barba con personalidades conocidas y anónimas del teatro latinoamericano le ha llevado a interactuar intensamente con tres generaciones de grupos y artistas.

Si analizamos cómo se cruzan los dos ejes en los siete libros antes mencionados obtenemos un contexto que organiza el conjunto. Este contexto no es una estructura rígida, es más bien una estructura profunda que da un sentido implícito a cada libro. Barba no diseñó esta estructura a priori. Desembocó en ella a través de una dramaturgia textual orientada a conceptualizar el sentido de las elecciones y experiencias que marcaron profundamente su trayectoria profesional. El resultado es una reflexión que transforma la propia identidad en una poética teatral.

Barba ha respondido a las cuatro preguntas de una manera implícita, a través de su práctica teatral. Pero también de una forma explícita, a través de sus libros más importantes. Y lo ha hecho apoyándose en cada caso en el diálogo con una de las tres culturales teatrales. Evidentemente en la práctica profesional el "dónde", el "por qué", el "cómo" y el "para 


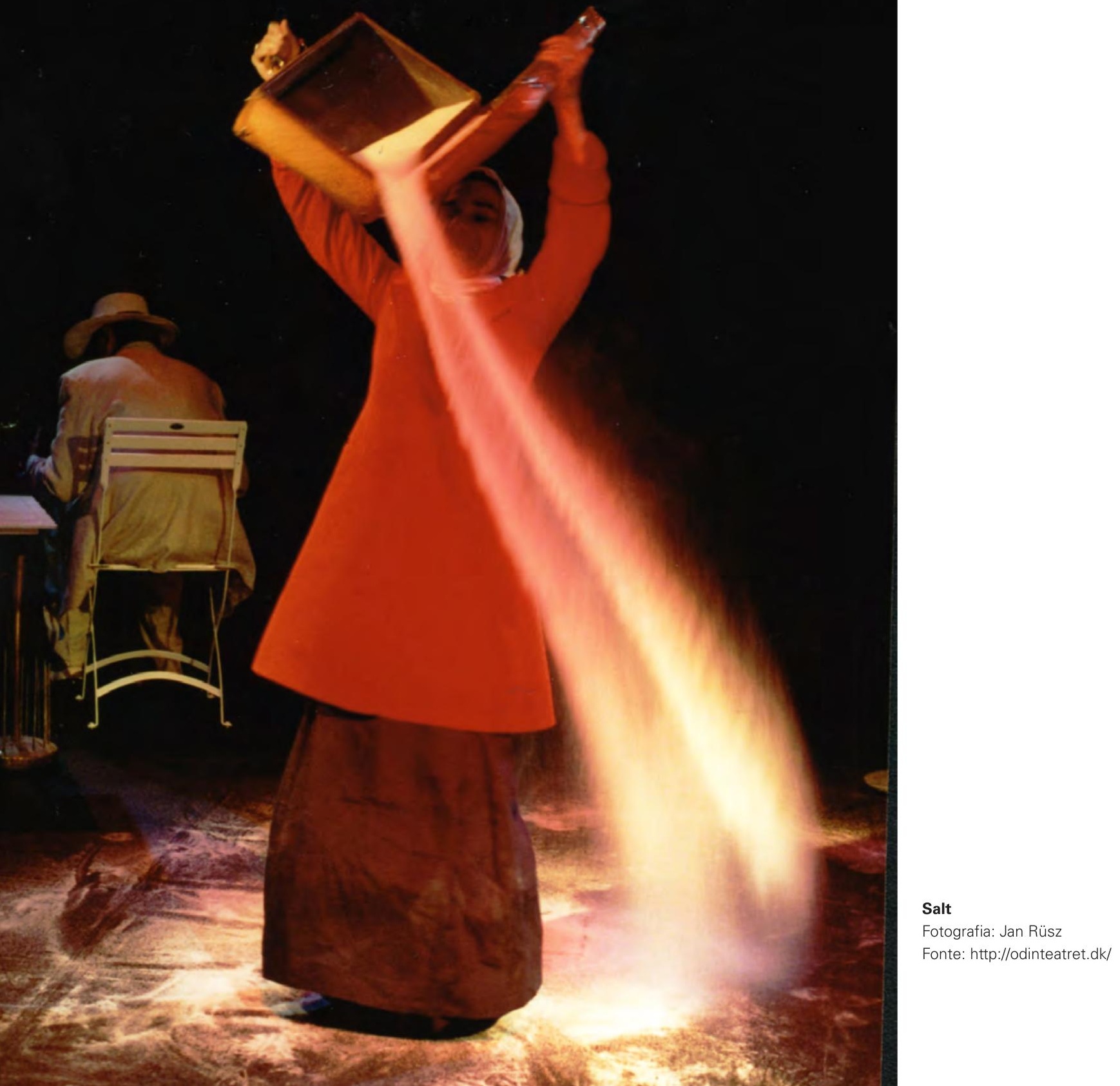


quién" hacer teatro aparecen fundidos en una realidad orgánica donde no es posible separarlos con claridad. Sin embargo, en el corpus escrito de Barba las cuatro preguntas tienden a ser extrapoladas y pensadas cómo si fueran una realidad en sí misma: cuatro niveles de organización del oficio. Esta forma de proceder le permite focalizar las cuestiones claves de cada nivel y, a partir de ahí, determinar con precisión la función de los cuatro niveles dentro de su visión teatral.

En este sentido, la obra escrita de Barba es un caso singular en el contexto del siglo XX: pocos directores han generado un corpus escrito que sea, a la vez, tan extenso por lo que se refiere al número de textos, tan amplio y detallado por lo que se refiere a las cuestiones que aborda y la profundidad con que lo hace, y tan bien estructurado por lo que se refiere a la coherencia de su pensamiento. ${ }^{4}$

\section{¿Dónde hacer teatro? La importancia del aprendizaje}

Barba ha conceptualizado la primera pregunta vinculándola a su aprendizaje. El libro donde explora esta cuestión es La tierra de cenizas y diamantes. Mi aprendizaje en Polonia seguido de 26 cartas de Jerzy Grotowski a Eugenio Barba. En él explica cómo llegó a Polonia para estudiar teatro en la escuela oficial de Varsovia y como, pasada la euforia de los primeros meses, el programa de estudio empezó a causarle una insatisfacción cada vez mayor. Hasta que a medio curso, en enero de 1962, aceptando una sugerencia de Jerzy Grotowski, decidió abandonar la escuela para convertirse en el ayudante de dirección del joven director polaco. Grotowski tenía 27 años y Barba 25. Como es sabido, en aquel momento Grotowski dirigía, junto a Ludwik Flaszen, un pequeño teatro de provincia, el Teatro de las 13 filas; no era conocido internacionalmente y en Polonia era considerado una figura muy periférica que contaba más bien poco en el contexto de la vida teatral. Barba permaneció con Grotowski del 1962 al 1964, justo el período en el que el director polaco transformó el Teatro de las 13 filas en un teatro laboratorio.

Un detalle importante que Barba cuenta en el libro es la perplejidad de sus profesores y compañeros en Varsovia ante su decisión de dejar la escuela por el Teatro de las 13 filas. Les costaba entender que abandonara la centralidad de la escuela más importante de Polonia para irse a la pequeña ciudad de Opole a trabajar con un personaje excéntrico y alejado de los 
circuitos teatrales importantes. Trabajando con Grotowski Barba entra en contacto con una manera completamente distinta de pensar y practicar el teatro; descubre una dimensión ética del oficio que luego reencontrará en los textos y la obra de los reformadores del siglo XX.

¿Dónde hacer teatro? En un teatro laboratorio. Este es un concepto que ha obsesionado a Barba hasta la actualidad y sobre el que ha reflexionado mucho. Barba lo vincula con el intento de enraizar el teatro al margen de las lógicas del mercado, creando un contexto donde es posible realizar y pensar el oficio como una investigación indisociable de la dimensión ética.

En la estructura global de la obra escrita de Barba, La tierra de cenizas y diamantes sugiere que el aprendizaje es también un nivel del oficio. Barba considera que el aprendizaje hay que realizarlo con un maestro, porque es de esta forma que se convierte en un proceso que va más allá de la mera adquisición de unas bases técnicas. El aprendizaje debe ser también un proceso en el que, a través de la técnica, se incorpora la dimensión ética del oficio. El sentido implícito del libro es que cada cual debería ser capaz de encontrar a su maestro, de hacerse aceptar por él, de convertirlo en superego profesional cuya función es catalizar las propias potencialidades. Dejarse influenciar totalmente por un maestro es la premisa para luego poder personalizar el conocimiento recibido, descubrir la libertad y transformarla en una identidad profesional individualizada, que se desarrolla como un diálogo continuo con el propio origen profesional.

\section{¿Por qué hacer teatro? La búsqueda del sentido personal}

El libro donde Barba explora la importancia del sentido personal es Teatro. Soledad, oficio, revuelta. A través de un montaje de 28 textos individuales el autor reflexiona sobre la motivación que ha galvanizado su trayectoria profesional con el Odin Teatret. En este libro el diálogo con Grotowski se expande a los reformadores teatrales del siglo XX. Barba se refiere a esa cultura teatral con el nombre de "la tradición de los fundadores de tradición" y la lee como una especie de genealogía profesional.

El libro bucea en una corriente subterránea que alimenta las visiones de los grandes reformadores, la corriente del sentido personal. Barba descifra en esta corriente una idea recurrente: negar el sentido establecido del teatro para inyectar en él otros valores que trasciendan su 
dimensión estética o artística. Si los reformadores negaron la práctica del oficio tal como estaba establecida en su época fue para convertirla en algo más que teatro: acción política, social, espiritual, antropológica, terapéutica o pedagógica en el sentido más amplio de la palabra.

Para Barba la búsqueda de un sentido personal del oficio es lo que permite llevar el teatro más allá de su dimensión artística. Ésta es la idea clave del libro. El teatro es una estrategia para poder vivir de otra forma, con otros valores, en otro contexto. El teatro es el caballo de Troya que permite realizar una actividad reconocida socialmente y al mismo tiempo rechazar los valores establecidos. La práctica teatral es, para Barba, el camino del rechazo. Rechazo del espíritu del tiempo, pero ante todo, rechazo del propio "teatro". Es decir, rechazo de todo lo que la sociedad de la época entiende y engloba bajo la etiqueta "teatro". La actitud ética de negar el sentido establecido del teatro es la premisa indispensable para potenciar y encontrar el sentido personal.

Dentro de la obra escrita de Barba, Teatro. Soledad, oficio, revuelta es una especie de autobiografía profesional que intenta recrear sobre el papel la propia búsqueda del sentido. A través de múltiples metáforas, el libro apunta constantemente a la realidad esencial de un teatro hecho para trascenderse a sí mismo. Este es el hilo rojo que cose el libro: la tensión entre el teatro y todo aquello que lo trasciende. Para el director del Odin el teatro como bien cultural o realidad artística no se justifica a sí mimo. Es una realidad que sólo vale si somos capaces de revitalizarla colocando en su corazón motivaciones muy personales. Entonces, la operación de buscar el sentido personal y de rellenar la cáscara del teatro transformándolo en algo más, es también un nivel del oficio.

\section{¿Cómo hacer teatro? La construcción de la técnica}

En la obra escrita de Barba la construcción de la técnica se desdobla en dos ámbitos: la técnica del actor y la técnica del director relativa a la composición global del espectáculo.

Los dos libros donde él conceptualiza su construcción de la técnica actoral son La canoa de papel y El arto secreto del actor (el segundo, escrito con Nicola Savarese y con la inclusión de textos de otros autores). Para analizar este nivel del oficio Barba se apoya en el diálogo con los teatros clásicos asiáticos. Este diálogo se profundizó mucho a partir de 1980 con la creación 
de la ISTA (International School of Theatre Anthropology) y la propia Antropología Teatral como una disciplina de estudio orientada a formular los principios pre-expresivos de la presencia escénica. Los teatros clásicos asiáticos fueron fundamentales como punto de partida para formular estos principios. Posteriormente, Barba amplió ese diálogo incluyendo en él las principales técnicas performativas de Europa y Norteamérica, o la danza afro-brasileña de los orixás.

En 1980, cuando Barba empezó a desarrollar la Antropología Teatral, el Odin ya era un grupo reconocido internacionalmente con 16 años de experiencia profesional. Sus actores veteranos habían recorrido un largo proceso de trabajo que desembocó en una notable capacidad técnica. La pregunta ¿cómo hacer teatro? ya había sido respondida de una manera implícita, desde la práctica. Los teatros clásicos asiáticos no enseñaron a Barba y sus actores cómo hacer teatro. Pero fueron fundamentales para conceptualizar qué aprende un actor cuando incorpora una técnica.

A través de la Antropología Teatral Barba ha desplegado un análisis del saber performativo pensado en categoría de principios y no de reglas. Este cambio de foco permite, tal como dice Barba, "aprender a aprender." Este es el fundamento de la técnica actoral tal como la ha desarrollado el Odin Teatret. Es una visión que ha permitido a cada actor crear su propio training y su propia dramaturgia actoral dentro del grupo. De esta forma, el contexto del Odin Teatret ha generado una práctica actoral que no es monolítica; más bien nace de la tensión dialéctica entre lo uno y lo múltiple. Su principal característica es la polaridad dinámica entre el substrato del saber actoral y las muchas maneras de aplicarlo, entre unas bases comunes y unos métodos individuales, entre la unidad de principios y la diversidad de procesos.

El libro donde Barba ha expuesto su visión de la técnica del director es Quemar la casa. Desarrollando una compleja reflexión sobre la dramaturgia, Barba expone una manera de organizar el proceso creativo de un espectáculo. Se trata de entrelazar la dramaturgia de los actores, la dramaturgia del director y la dramaturgia de los espectadores. El director del Odin Teatret formula una serie de principios y lógicas pragmáticas orientadas a convertir el espectáculo en un "ritual vacío". Con esa idea Barba intenta evitar la construcción de un espectáculo que tenga un sentido claro, unívoco, que deberían entender y captar todos los espectadores. Pero también se trata de evitar lo contrario, que el espectáculo no tenga sentido. El 
espectáculo adquiere el valor de un ritual porque ha sido cuidadosamente construido para fijar un montaje de acciones y materiales. Y ese ritual está "vacío" porque responde al objetivo de crear una potencialidad de sentido lo más amplia posible. Cada actor, el propio director y cada uno de los espectadores deberían hallar en el espectáculo las herramientas y los estímulos necesarios para construir o descubrir un sentido personal, íntimo e intransferible. El espectáculo, entonces, se convierte en una realidad objetiva a través de la cual cada uno puede dialogar con su subjetividad profunda, a la que Barba se refiere a menudo con la expresión "aquella parte de nosotros que vive en exilio".

Dentro de su poética teatral Barba otorga a la técnica la función de una premisa o un catalizador. No es lo esencial, pero es indispensable para plasmar las motivaciones personales en acciones reales. Sin el dominio de la técnica las motivaciones personales pueden convertirse muy fácilmente en una retórica inoperante y con tendencia al solipsismo. Al pensar la construcción de la técnica (del actor y del director) en categorías de principios, Barba la convierte en una herramienta eficaz y sólida para materializar los propios porqués. De este modo la técnica puede trascender el plano de la habilidad artística para convertirse en la praxis de una ética.

\section{¿Para quién hacer teatro? La conquista del valor}

Sin unas motivaciones personales fuertes, que a menudo son difíciles de descifrar, no es posible trascender el teatro. Pero si uno no es capaz de concretar sus motivaciones personales en espectáculos eficaces para dialogar con los espectadores, la ética que las nutren se vuelve irreconocibles para los demás. La complementariedad del sentido personal y la técnica es lo que crea el cuarto nivel del oficio, tal vez el más enigmático: el valor.

Cuando el sentido personal de una práctica teatral puede ser reconocido y compartido por otras personas se convierte en un valor. Entonces, para algunos espectadores esa práctica adquiere un extraño magnetismo que va más allá de la belleza o el poder expresivo del espectáculo.

Si el sentido personal del oficio se dirime en su capacidad de satisfacer las necesidades profundas de los hombres y mujeres que hacen teatro, el valor del oficio se dirime en su capacidad de conectar con las necesidades profundas de los espectadores. El valor de un teatro no 
lo deciden las personas que lo hacen; es un intangible que le otorgan los espectadores cuando perciben en esa práctica teatral una ética que reconocen y en la que se reconocen. Para Barba el valor de un teatro no tiene que ver con la originalidad o la perfección estética, sino con su capacidad de nutrir la lucha, las aspiraciones y las obsesiones de los espectadores.

\section{Pero en la práctica del oficio, ¿cómo se conquista el valor?}

El libro donde Barba ha explorado y explicado su propia conquista del valor es Arar el cielo. Diálogos latinoamericanos. En el nivel del valor, la obra de Barba contiene dos conceptos fundamentales. El primero es el concepto de "espectador". El director del Odin siempre ha rechazado la categoría abstracta de "público" para centrarse en la individualidad del espectador. El público es un grupo anónimo y sin rostro. El espectador es una persona con una biografía específica que acude a ver el espectáculo. Para proteger la relación personal con el espectador el Odin Teatret siempre ha intentado construir una relación de proximidad con él. Por ejemplo limitando el aforo de sus espectáculos. Otra forma de potenciar la individualidad del espectador es la técnica dramatúrgica de Barba cuya finalidad es, como hemos visto, convertir el espectáculo en un ritual capaz de susurrar algo íntimo al oído de cada persona. Estas estrategias responden a la necesidad vital de encontrar los "propios" espectadores; aquellos que, a su vez, reconocen el Odin como "su" teatro.

Aquí aparece el segundo concepto clave que Barba relaciona con la conquista del valor: lo que él llama el "pueblo secreto". Con esa formulación a ese núcleo de espectadores que se identifican con el Odin Teatret porque reconocen en su manera de practicar el oficio unos valores en los que creen profundamente. Es así cómo un teatro puede volverse necesario para un puñado de espectadores y conquistar, en consecuencia, un valor preciso.

El estrato más profundo de la poética teatral de Barba consiste en transformar el teatro en una patria invisible donde es posible tejer relaciones humanas profundas. Él se refiere al "pueblo secreto" del Odin Teatret con algunas metáforas: "aquellos que no pertenecen al mundo en el cual viven", "campesinos que cultivan semillas de disidencia", "fabricantes de sombras indelebles", "caballeros con espadas de agua", "guerrilleros de la obstinación". 


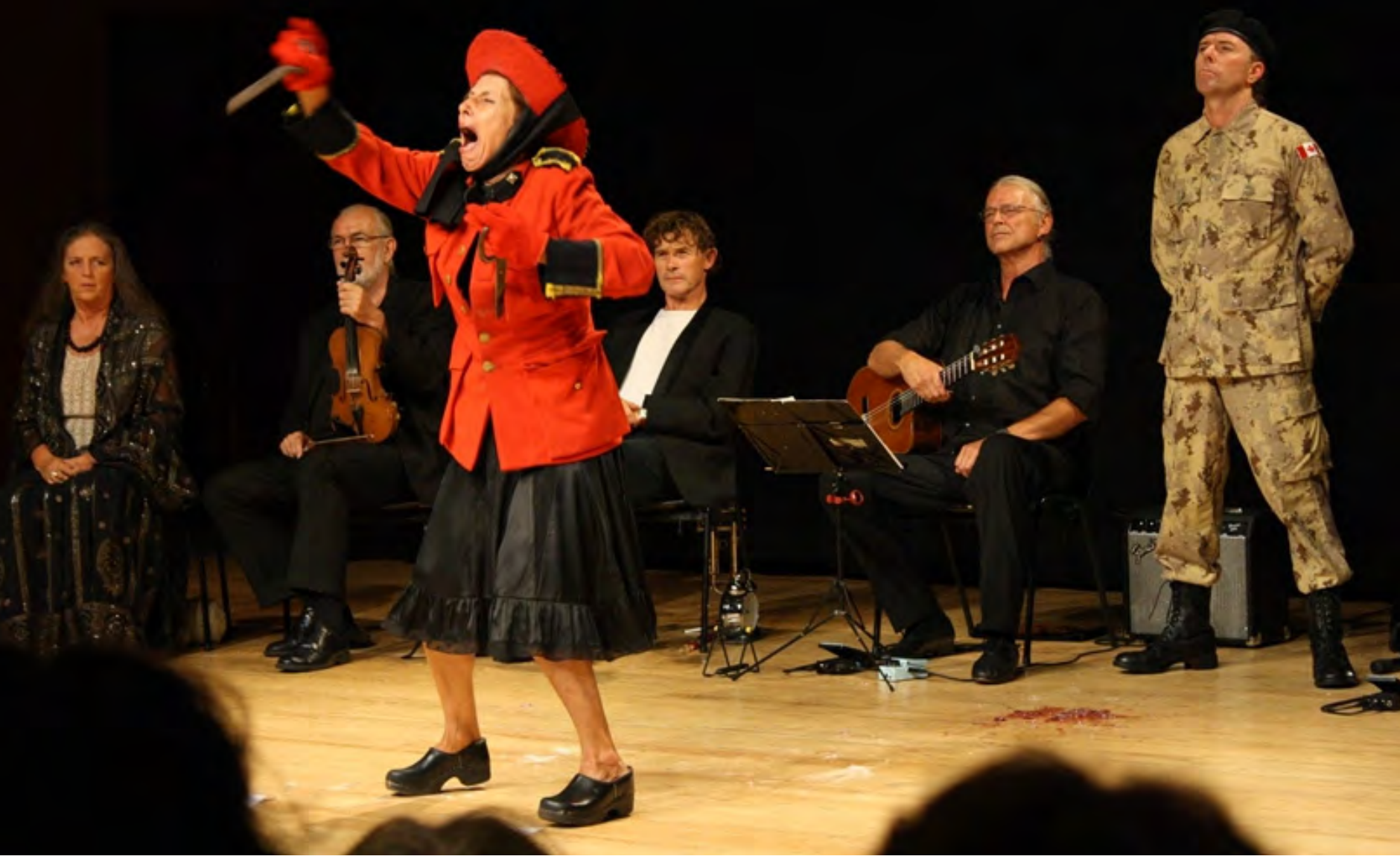

The Great Cities Under the Moon

Fotografia: Rina Skeel

Fonte: http://odinteatret.dk/ 
La cuestión del valor aparece conceptualizada en la obra de Barba cada vez con más intensidad en los textos del siglo XXI. Y es la clave que explica porque, a partir de un determinado momento, sus textos tienden a adoptar la forma de una carta abierta dirigida a una persona concreta o a un grupo de personas.

Al explorar el nivel del valor, la cultura teatral que ha sido más decisiva para Barba es el teatro de grupo latinoamericano. Se ha reflexionado mucho sobre la influencia de Barba y el Odin Teatret sobre ese sector del teatro latinoamericano. Pero se ha subrayado mucho menos el efecto de esa cultura teatral sobre Barba. Es una influencia ha sido fundamental para conceptualizar la importancia y la función del valor. Barba ha repetido muchas veces que una parte esencial del "pueblo secreto" del Odin Teatret está en América Latina. El diálogo con algunos espectadores y colegas latinoamericanos es precisamente el contexto del libro Arar el cielo.

En la poética teatral de Barba el valor no es sólo una cuestión que pertenece a los espectadores. Es también un nivel del oficio donde aparecen algunas cuestiones profesionales concretas: ¿cómo identificar los propios espectadores? ¿Cómo colaborar con ellos a todos los niveles? ¿Cómo profundizar los lazos emotivos que se crean? ¿Cómo dar calidad y continuidad a esos vínculos? ¿Cómo ser leal a ese "pueblo secreto"?.

Estas cuestiones explican determinadas actitudes profesionales de Barba y el Odin Teatret. Por ejemplo su obsesión por dialogar y interactuar con los propios espectadores más allá del contacto fugaz del espectáculo; o la estrategia de poner el propio prestigio internacional al servicio de grupos anónimos y organizaciones teatrales más bien periféricas para fortalecer su posición en el medio en el que trabajan; o contradecir las lógicas comerciales más elementales de un teatro para poder estar presente en determinados contextos o lugares, junto con personas con las cuales tiene un vinculo de simpatía, amistad o solidaridad. Podríamos pensar que todas estas actitudes profesionales constituyen un altruismo romántico, un derroche improductivo o un idealismo ingenuo que puede poner en peligro la supervivencia del propio teatro. Y sin embargo, es exactamente lo contrario: se trata de una calculada competencia profesional que tiene un objetivo muy preciso: nutrir la dinámica interna del grupo, la consciencia de su propia responsabilidad y la necesidad de su resistencia.

Cuando se habla del Odin Teatret a menudo surge una pregunta recurrente. ¿Cuál es el secreto de su resistencia? En noviembre de 2014 el Odin Teatret va a cumplir 50 años. ¿Cómo puede una pequeña compañía teatral resistir 50 años con un núcleo invariable de personas? 
No hay sólo una razón para explicar la longevidad del Odin Teatret, pero u una de sus claves reside en la función del "pueblo secreto". Aglutinar y alimentar ese "pueblo secreto" que dé valor a la propia praxis del oficio es fundamental para resistir. Porque para perdurar en el tiempo, una pequeña compañía no sólo necesita dinero y recursos materiales. Necesita también palpar la conciencia de que ese teatro es necesario para un grupo de espectadores; debe tener la convicción que la propia acción incumbe a otras personas fuera del grupo; necesita saber que no tiene derecho a abandonar su lucha. La conquista del valor es un nivel del oficio que no es obvio ni reconocible a simple vista. Y sin embargo es esencial para un teatro que quiera trascenderse a sí mismo.

\section{La conquista de la diferencia}

Éste es por el momento el último libro de Barba. La edición italiana, la más completa, es un montaje de 39 textos del cual emerge una síntesis de su visión teatral. Des de la perspectiva de este artículo lo más relevante del libro es que recorre los 4 niveles de organización del oficio. No lo hace de una forma lineal, sino a través de un collage que intenta mostrar la complejidad global del oficio, tal como lo entiende Barba. En sus anteriores libros el director del Odin Teatret centraba su atención en un nivel del oficio. Por el contrario, el principal tema de La conquista de la diferencia es la profunda interrelación de los cuatro niveles que organizan la globalidad de su visión teatral.

La identidad profesional de Barba es la "conquista de la diferencia". Una diferencia que se fraguó a principios de los años sesenta en Opole y dio un gran rodeo por Asia para acabar desembocando en Latinoamérica. Una diferencia que se ha desarrollado a través de una serie de lealtades concéntricas hacia un maestro (Grotowski), una genealogía de antepasados profesionales (los reformadores del siglo XX), los propios actores y el puñado de espectadores que constituyen el "pueblo secreto" del Odin Teatret.

\section{Notas}

1 A lo largo del artículo doy siempre las referencias bibliográficas de los libros de Barba (o de los actores del Odin Teatret) que han sido publicados en España. Cuando el libro en cuestión no ha sido publicado en España, doy la referencia bibliográfica de las ediciones en español publicadas en Latinoamérica. "A continuación doy la referencia bibliográfica de las traducciones al portugués. Arar el cielo: 
diálogos latinoamericanos y La conquista de la diferencia no han sido aún traducidas a esta lengua. A terra de cinzas e diamantes. Minha aprendizagem na Polônia. Seguido de 26 cartas de Jerzy Grotóvski a Eugenio Barba, São Paulo, Editora Perspectiva, 2006 Além das ilhas flutuantes, São Paulo-Campinas, Editora Hucitec-Unicamp 1991; Teatro. Solidâo, ofício, revolta, ed. by Lluís MASGRAU, Brasilia, Dulcina, 2011; A arte secreta do ator. Um dicionário de antropologia teatral, by E. BARBA and N. SAVARESE. São Paulo, É Realizações Editora, 2012; A canoa de papel. Tratado de Antropologia Teatral, São Paulo, Hucitec, 1994/ Brasilia, Dulcina, 2009; Queimar a casa. Origens de um director, Sâo Paulo, Perspectiva 2010.

2 Este es el título de la tercera y definitiva versión del libro. La primera y segunda versión llevaban por título Las islas flotantes (Universidad Nacional Autónoma, México D.F. 1983; existe también una edición española en catalán, Les illes flotants, Institut del Teatre y Edicions '62, Barcelona 1983) y Más allá de las islas flotantes (Gaceta Editorial, México D.F. 1986 y Firpo-Dobal, Buenos Aires 1987).

3 La edición peruana es la primera versión del libro. Posteriormente Barba publicó con el mismo título una segunda versión en italiano que es más amplia y tiene una estructura diferente (Bulzoni, Roma 2012). La edición cubana de 2012 reproduce la versión italiana.

4 Como complemento al corpus escrito de Barba cabe citar los siguientes libros de sus actores: Iben Nagel-Rasmussen, El caballo ciego (Alarcos, La Habana 2013) y Den fjerde dør (La cuarta puerta, sólo publicado en danés por Nyt Nordisk Forlag Arnold Busch, Copenhague 2012); Roberta Carreri, Rastros. Historia y training de una actriz del Odin Teatret (Artezblai, Bilbao 2011); Julia Varley, Piedras de agua. Cuaderno de una actriz del Odin Teatret (Artezblai, Bilbao 2011). 